\title{
Helen HARDEN CHENUT, The Fabric of Gender: Working- Class Culture in Third Republic France
}

University Park, Pa., Pennsylvania State University Press, 2005, ix + 436 p.

\section{Siân Reynolds}

\section{(2) OpenEdition}

1 Journals

\section{Édition électronique}

URL : http://journals.openedition.org/clio/9541

DOI : $10.4000 /$ clio.9541

ISSN : 1777-5299

Éditeur

Belin

Édition imprimée

Date de publication : 15 décembre 2009

ISSN : 1252-7017

Référence électronique

Siân Reynolds, " Helen harden chenut, The Fabric of Gender: Working-Class Culture in Third Republic France », Clio. Histoire, femmes et sociétés [En ligne], 30 | 2009, mis en ligne le 24 mars 2010, consulté le 21 septembre 2020. URL : http://journals.openedition.org/clio/9541 ; DOI : https://doi.org/10.4000/ clio.9541

Ce document a été généré automatiquement le 21 septembre 2020.

Tous droits réservés 


\section{Helen HARDEN CHENUT, The Fabric of Gender: Working-Class Culture in Third Republic France}

University Park, Pa., Pennsylvania State University Press, 2005, ix +436 p. ${ }^{1}$

\section{Siân Reynolds}

\section{RÉFÉRENCE}

Helen HARDEN CHENUT, The Fabric of Gender: Working-Class Culture in Third Republic France, University Park, Pa., Pennsylvania State University Press, 2005, ix + 436 p. ${ }^{2}$

1 Lors d'une grève dans la bonneterie troyenne en 1921, un incident s'est produit dont les archives ne gardent quasiment pas de trace, mais qui est resté dans la mémoire populaire. Un patron d'usine est séquestré par une foule en colère : on parle même de le faire pendre. L'intervention, paraît-il, d'une femme, syndicaliste, lui sauve la vie : elle propose qu'on l'humilie plutôt,en l'envoyant éplucher des pommes de terre. On se calme, et le patron est conduit aux autorités municipales ${ }^{3}$.

2 Pour son étude en profondeur de la communauté ouvrière de Troyes, ouvrage sur le chantier depuis plus d'une vingtaine d'années, Helen Harden Chenut a pu récupérer les témoignages oraux des participant(e)s à une histoire qui nous semble maintenant très éloignée. Mais ce n'est pas là le seul avantage d'un travail de longue haleine. Le livre de $\mathrm{H}$. Chenut prend ses origines dans une thèse inscrite dans l'histoire du travail et commencée dans les années 1970-1980, alors que les études sur le mouvement ouvrier avaient le vent en poupe. Dans un colloque récent, consacrée à la mémoire de Madeleine Rebérioux, il a parfois été question de la marginalisation actuelle de la recherche sur le socialisme, le travail et le mouvement ouvrier en France, face à la montée de l'histoire culturelle depuis le "tournant linguistique", face aussi à la chute de l'Union soviétique et à la mondialisation ${ }^{4}$. 
3 Ce pessimisme s'explique en partie par la disparition ou la retraite d'une génération particulièrement brillante d'historiens et d'historiennes inspirée par Ernest Labrousse, qui avaient contribué à une sorte d'âge d'or de l'histoire ouvrière, autour de la revue Le Mouvement social (bien vivante aujourd'hui, Dieu merci !). Mais c'est faire peu de cas des générations de chercheurs/chercheuses, français ou non, qui ont occupé le terrain depuis les années 1970 et qui y ont apporté de nouvelles approches. Un des aspects les plus saisissants de l'histoire nouvelle manière est la place de plus en plus assurée du genre en tant qu'instrument d'analyse. Même si en France elle-même, ni le mot ni la chose n'ont eu le passage facile, le temps n'est plus, comme l'observe H. Chenut, où elle était obligée d'employer l'expression "rapports sociaux de sexe".

4 Son étude "gendered"/genrée ? de Troyes, ville de la bonneterie, présente le grand avantage d'avoir su concilier les données empiriques de la thèse originale scrupuleusement axée sur la production textile, la technique et les métiers masculins et féminins - et les changements progressifs d'optique qu'ont apportés non seulement l'histoire des femmes et du genre, mais aussi l'analyse des cultures et des mentalités. En ceci, Helen Chenut montre combien elle est proche de Michelle Perrot, directrice de sa thèse, qui a su, avec une subtilité notoire, unir la maîtrise des idées nouvelles à l'étude de groupes humains dans le monde réel, et poursuivre 'les silences de l'histoire'. Helen Chenut reconnaît également sa dette envers le penseur gallois marxisant Raymond Williams, trop peu connu en France, pour lequel la culture était "processus social total", englobant travail, loisirs, consommation, liens familiaux et amicaux ${ }^{5}$. À l'intérieur de n'importe quelle culture, selon lui, on trouve non pas cohérence mais contradictions, complicités et résistances, perceptibles dans les menus faits de la vie quotidienne.

5 C'est donc à la culture totale de la classe ouvrière à Troyes - et le mot classe ne fait pas peur à $\mathrm{H}$. Chenut - que ce livre est consacré. Il commence par un récit détaillé de la grande grève de 1900, qui exposa les tensions à tous les niveaux : entre patrons et ouvriers, travailleurs qualifiés et non qualifiés, jeunes et moins jeunes, hommes et femmes, syndicats et partis politiques. Ensuite, des chapitres traitent tour à tour de l'histoire de la production textile en Champagne, avec l'émergence d'un système mixte d'usines en ville et de travail à domicile dans la région; de l'histoire conflictuelle d'une conscience de classe exprimée plus volontiers à travers le syndicalisme et le coopératisme que par l'intermédiaire du parti socialiste, en l'occurrence guesdiste; et $\mathrm{du}$ quotidien du travail des bonnetiers/bonnetières. Le chapitre 4 nous mène au cœur de l'expérience ouvrière, avec des témoignages sur les processus de la production: bobinage, tricotage, remaillage et raccoutrage sur le recrutement, l'apprentissage et surtout la division sexuée du travail. H. Chenut pose des questions inhabituelles sur la vie d'usine : comment faisait-on pour garder les enfants (p.198) ? Réponse : des réseaux familiaux, ou le travail à domicile. $Y$ avait-il des moments de coopération (complicité ?) entre patrons et ouvriers ? Oui, la Fête annuelle de la bonneterie, avec tout ce qu'elle comportait d'ambiguïté, particulièrement en ce qu'elle célébrait les ouvrières, moins rémunérées pour la plupart. Le chapitre 6 décrit la féminisation accrue de la bonneterie après la Grande Guerre, développement lourd d'inégalités.

6 La seconde partie du livre, qui s'étend sur l'entre-deux-guerres, introduit de nouveaux éléments. La bonneterie c'est le vêtement, mais comment les ouvriers s'habillaient-ils, ou elles? Utilisant des photos classiques de sorties d'usine et des images de publicité, dans deux chapitres sur la consommation ouvrière et la recherche de marchés 
nouveaux, Helen Chenut explore la question des modes et du changement dans la société française d'après-guerre. Si les cheveux coupés et les jupes courtes des femmes tendent dans une certaine mesure à gommer des différences sociales, la casquette de l'ouvrier, en revanche, accentue la masculinité ouvrière (p. 303). En particulier, H. Chenut retrace la fortune du magasin coopératif La Laborieuse, devenu pendant de longues années le centre de consommation de toute une communauté, en vendant à ses membres produits alimentaires, vêtements, services, etc., mais aussi en ouvrant bibliothèques et salles de lecture. Symbole d'une solidarité de classe, elle a succombé à la crise des années 1930, pour s'amalgamer à un organisme dont les pratiques étaient "plus capitalistes" (p. 333). Le dernier chapitre traite des confrontations pendant la crise et sous le Front Populaire, en soulignant le peu de gains acquis par les ouvriers, vu les blocages qui ont suivi le mouvement de juin 36, et en particulier les gains négligeables des femmes, dans un contexte de négociations qui consacrait des définitions traditionnelles de la qualification.

7 Ces derniers points ne sont pas nouveaux, mais confirment l'image de Troyes comme microcosme de la France divisée, à la veille de la Seconde Guerre mondiale. Les conclusions du livre indiquent que certaines idées-forces devraient être prises en considération quand on écrit l'histoire du travail industriel du premier vingtième siècle : le développement inégal et non linéaire de l'industrie textile; l'agressivité à peine diminuée des patrons, refusant de négocier sérieusement les conditions du travail ; la contre-culture des ouvriers, forme de résistance qui permettait l'espoir, alors même que les espérances de vie dans la classe ouvrière sont restées désespérément basses jusqu'aux années 1920 (p. 393); le rôle de la consommation, créant une solidarité certaine, mais aussi, en fin de compte, intégrant la vie ouvrière dans la société française en ouvrant de nouveaux horizons ; et finalement l'importance du genre pour une histoire "totale" de la France industrielle et de la culture ouvrière.

8 Ce livre dense et riche ne se résume pas facilement. Certains chapitres sont mêmes d'un abord un peu difficile (sur la vie politique locale notamment). Mais cette étude de cas est un modèle du genre: la longue familiarité de l'auteure avec les lieux et les personnes; sa connaissance profonde de la vie concrète et ses analyses réfléchies, ont contribué à fabriquer de Troyes, des Troyens et des Troyennes, un tout qui est un véritable lieu de mémoire.

\section{NOTES}

1. Une traduction française du livre paraîtra aux Presses universitaires de Rennes en 2010.

2. Une traduction française du livre paraîtra aux Presses universitaires de Rennes en 2010.

3. Il s'agit de Suzanne Gallois, témoin privilégié, et militante très active, très présente dans le livre. Son témoignage est précieux, mais il convient de noter qu'elle ne représente pas forcément le commun des ouvrières.

4. Colloque du 5-6 février 2009, «Qu'est devenue l'histoire du socialisme : hommage à Madeleine Rebérioux ", Assemblée Nationale, Paris ; dans son rapport pour la table ronde sur le féminisme, Françoise Thébaud a d'ailleurs contesté ce déclin en ce qui concerne l'histoire des femmes et du 
genre, en indiquant à la fois que «les recherches se sont déplacées vers d'autres lieux que l'usine », et que d'autres historiographies, hors de France 'restent fort imprégnées de l'histoire sociale'. Je puis confirmer ce dernier point en ce qui concerne les pays anglophones, qu'il s'agisse de leur propre histoire ou précisément de l'histoire de France.

5. Parmi les écrits de Raymond Williams (1921-1988), voir par exemple Culture and Society (1958), Communications (1966) et Keywords (1984). 